\section{Effect of Early Correction of Hyponatremia on Neurological Outcome in Traumatic Brain Injury Patients}

\section{Abstract}

Background: Hyponatremia is common in neurocritical care. If it is timely corrected, it can prevent deadly complication like brain edema and may improve overall prognosis in these patients.

Methods: Retrospective analysis of 150 patients of traumatic brain injuries who developed hyponatremia during stay in intensive care unit (ICU) was performed. Neurological outcome was defined on the basis of Glasgow Coma Scale (GCS), comparing GCS on admission and GCS at the time of discharge from ICU. Good neurological outcome was defined, if GCS improved significantly as compared to admission and poor neurological outcome if GCS remained same or deteriorated than admission or patient died during ICU stay. On the basis of correction of serum sodium within $48 \mathrm{~h}$ of onset of hyponatremia, two groups (correction achieved or not) were compared to the neurological outcome groups, as defined earlier. Chi Square test and Multiple Logistic Regression Model were used to assess association between correction of hyponatremia within $48 \mathrm{~h} \&$ neurological outcome. Data was analyzed by SPSS Version 21 and Stata Statistical Package 13. P value $<0.05$ was considered significant.

Results: Majority of patients were male, $88 \%$ versus $12 \%$ of females. Mean age remained 32.7 years. In 108 patients correction of hyponatremia was achieved within $48 \mathrm{~h}$ and in 42 cases it took longer time to correct. Good neurological outcome was seen in $83 \%$ cases and poor outcome in $17 \%$. Statistically significant association was seen between serum sodium correction within $48 \mathrm{~h}$ of onset and neurological outcome (Chi Square, $\mathrm{P}<0.0001$ ), (Logistic Regression analysis, $\mathrm{P}<0.001$ in univariate $\& 0.007$ in multivariate analysis).

Conclusion: There is significant association between early correction of hyponatremia and neurological outcome in traumatic brain injury patients.

Keywords: Traumatic brain injury; Hyponatremia; Intensive care unit; Neurological outcome; Glasgow coma scale; Brain edema; Acute hyponatremia

Received: January 19, 2017; Accepted: January 27, 2017; Published: February 03, 2017

\section{Introduction}

Hyponatremia is the most common electrolyte abnormality seen in critically ill patients [1]. Patients with polytrauma and traumatic brain injury are the most critically ill patients, and hyponatremia is frequently seen in these patients [2-4]. Hyponatremia is one of the common causes of secondary brain injury [5]. If it is not corrected promptly, it may cause serious complications such as
Khalil Ahmad', Zeyad Faoor Alrais², Hesham Mohamed Elkholy ${ }^{1}$, Adel Elsaid Elkhouly ${ }^{1}$, Maged Mohsen Beniamein ${ }^{3}$, Ammar Abdel Hadi ${ }^{1}$, Sohail Majeed ${ }^{4}$ and Ahmad Shoaib ${ }^{5}$

1 Surgical \& Neurosurgical Intensive Care, Trauma Centre Rashid Hospital, Dubai Health Authority, Dubai, UAE

2 Head Critical Care Section (Medical, Surgical \& Neurosurgical Intensive Care) Trauma Centre Rashid Hospital, Dubai Health Authority, Dubai, UAE

3 Medical Intensive Care, Trauma Centre Rashid Hospital, Dubai Health Authority, Dubai, UAE

4 Department of Neurosurgery, Rashid Hospital Dubai Health Authority, Dubai, UAE

5 Senior Clinical Research Fellow, University of Hull \& University of York, UK. Specialist Registrar Cardiology Whiston Hospital, UK

Corresponding author: Khalil Ahmad

\section{dkahmad786@yahoo.com}

Specialist Senior Registrar, Surgical \& Neurosurgical Intensive Care Unit, Trauma Centre Rashid Hospital Dubai Health Authority Dubai, UAE.

Tel: +971509106960

Citation: Ahmad K, Alrais ZF, Elkholy HM, et al. Effect of Early Correction of Hyponatremia on Neurological Outcome in Traumatic Brain Injury Patients. J Intensive \& Crit Care 2017, 3:1.

malignant brain edema leading to brainstem herniation, and eventually to death [6]. In this way hyponatremia can affect the 
overall neurological outcome and hospital morbidity \& mortality [7-10]. Hyponatremia is defined as if serum sodium level falls below $135 \mathrm{mmol} / \mathrm{L}$ [11]. If hyponatremia duration is less than $48 \mathrm{~h}$ it is called acute hyponatremia [12] and chronic if more than $48 \mathrm{~h}$ of onset [13]. Soon after hypotonic environment due to hyponatremia, compensatory mechanisms start working by extruding intracellular minerals (sodium \& chloride) and organic osmolytes to extracellular space to maintain water equilibrium between brain cells. It is the acute hyponatremia in which the chances of cerebral edema are more as compared to chronic one, as these compensatory mechanisms are not fully developed yet $[14,15]$. Thus, if serum sodium is not corrected during this time, the chances of complications like cerebral edema due to water shift into the brain cells are more which may lead to serious consequences [16]. In this way sodium correction during this duration (within first $48 \mathrm{~h}$ of onset) may directly correlate to the neurological outcome and can affect the overall prognosis [17].

All the traumatic brain injury (TBI) patients are classified into three severity classifications, according to the initial Glasgow Coma Scale (GCS); mild TBI (GCS 13-15), moderate TBI (GCS 9-12) and severe TBI (GCS 3-8) [18,19].

There are many studies done in the past to find out various factors affecting on neurological outcome, but to see early correction of hyponatremia affecting neurological outcome in traumatic brain injury patients, are scarce. Thus, this study was designed to determine the influence of the early hyponatremia's correction on neurological outcome in these patients.

\section{Methodology}

\section{Methods}

A retrospective analysis of 150 patients who were admitted to surgical, medical \& neurosurgical intensive care units (ICU) diagnosed with different traumatic brain injuries and developed hyponatremia during their ICU stay, was performed in a tertiary care hospital level one trauma center. All those patients who remained in a persistent shock state (MAP $<65 \mathrm{~mm}$ $\mathrm{Hg} \&$ persistent rising lactate), persistent hypoxia due to any reason (with persistent $\mathrm{PO}_{2}<60 \mathrm{~mm} \mathrm{Hg} \& \mathrm{SaO}_{2}<90 \%$ ), having concomitantly any metabolic encephalopathy, and fixed-dilated pupils with initial GCS 3/15 due to initial neurological insult, were excluded from the study. Two groups were defined on the basis of serum sodium (s. Na) correction ( $\geq 135 \mathrm{mmol} / \mathrm{l}$ ) within $48 \mathrm{~h}$ of detection, whether correction achieved or not. Hyponatremia was defined as serum sodium level $<135 \mathrm{mmol} / \mathrm{L}$. A lowest value of three readings $<135 \mathrm{mmol} / \mathrm{L}$ was recorded in each case, each reading $4 \mathrm{~h}$ apart. Neurological outcome was defined on the basis of comparing their GCS on admission to hospital (prior to endotracheal intubation) and at the time of discharge from ICU. Good neurological outcome was defined if GCS improved significantly than admission, i.e., in severe TBI if GCS improved $\geq$ 11 , in moderate TBI if GCS improved by $\geq 2$ scores, in mild TBI if GCS improved by $\geq 1$ score as compared to admission. In Severe TBI GCS is between 3-8, in moderate TBI between 9-12 and in mild TBI between 13-15. Both groups, neurological outcome group (Good/Poor) and sodium correction with $48 \mathrm{~h}$ (achieved or not), were compared to know statistical association between these two variables.

\section{Study design}

It was an observational descriptive analysis.

\section{Data Collection \& Statistical Analysis}

Data was collected by using Philip IntelliVue Portfolio-Clinical Information System, being used in our set up for documentation of patient clinical record. Categorical variables were described as frequencies or percentages, and continuous variables as mean $\&$ standard deviation (SD). Categorical variables (neurological outcome \& Na correction within $48 \mathrm{~h}$ ) were compared using Chi Square test and continuous variables (mean serum $\mathrm{Na}$ levels before \& after treatment) by Paired Student T Test. Multivariable Logistic Regression Model was used to know the association between neurological outcome and other factors including sodium correction with 48 hours. Data was analyzed by SPSS Version 21 for basic calculations as well Chi Square Test, and Stata Statistical Package 13 for Logistic Regression Model. An alpha value of $5 \%(P$ value $<0.05)$ and confidence interval of $95 \%$ was considered as significant statistically.

\section{Results}

The mean age remained $32.73 \pm 18.24$ SD years. Most common age groups remained $25-36$ years $31 \%(47 / 150) \& 37$ to 48 years $21 \%(32 / 150)$. Nine per cent $(13 / 150)$ belonged to above 60 years age group. Male patients were 132 (88\%) and eighteen (12\%) females. Seven patients (5\%) died amongst study population, and 143 (95\%) were discharged from the ICU after stabilizing and treating the initial injuries. Mean value of total length of stay (LOS) in ICU remained $16.16 \pm 9.8$ SD days (minimum of 2 days $\&$ maximum 55 days). The highest mean LOS was seen in severe TBI cases, $18.3 \pm 8.9$ SD days. Road traffic accident (RTA) and fall from height remained the two most common causes of TBI, $46 \%$ (70/150) \& 41\% (61/150), respectively. Other causes leading to initial TBI were, due to industrial accidents in 9\% (13/150), Sports injury in $2 \%(3 / 150), 2$ patients (1.3\%) due to assault and 1 case $(0.6 \%)$ due to gun-shot injury (Figure 1$)$. Sixty per cent $(90 / 150)$ patients were classified as severe TBI on the basis of initial GCS score, $19 \%(29 / 150)$ with moderate TBI and 21\% (31/150) with mild TBI (Figure 2). In 67\% (100/150) patients, mixed lesions with combination of two or more different TBI categories were noted. While solitary lesions were noted in $31 \%(47 / 150)$ cases, such as extradural hematoma, contusion hematoma, traumatic subarachnoid hemorrhage \& traumatic intraventricular hemorrhage. Diffuse Axonal Injury (DAI) was diagnosed in $2 \%$ (3/150) cases on the basis of clinical \& Magnetic Resonant Imaging (MRI) findings (Figure 3). The most common mode of GCS on admission was found 8 (23 patients out of 150,15\%). The most common mode of GCS at the time of discharge from ICU remained 15 (64 patients out of 150,43\%). Amongst the 90 cases with severe TBI, 38 (42\%) patients had initial GCS 3-5 \& 52 (58\%) patients with GCS between $6-8$. In $54 \%$ (81/150) patients different neurosurgical procedures were performed like decompressive 

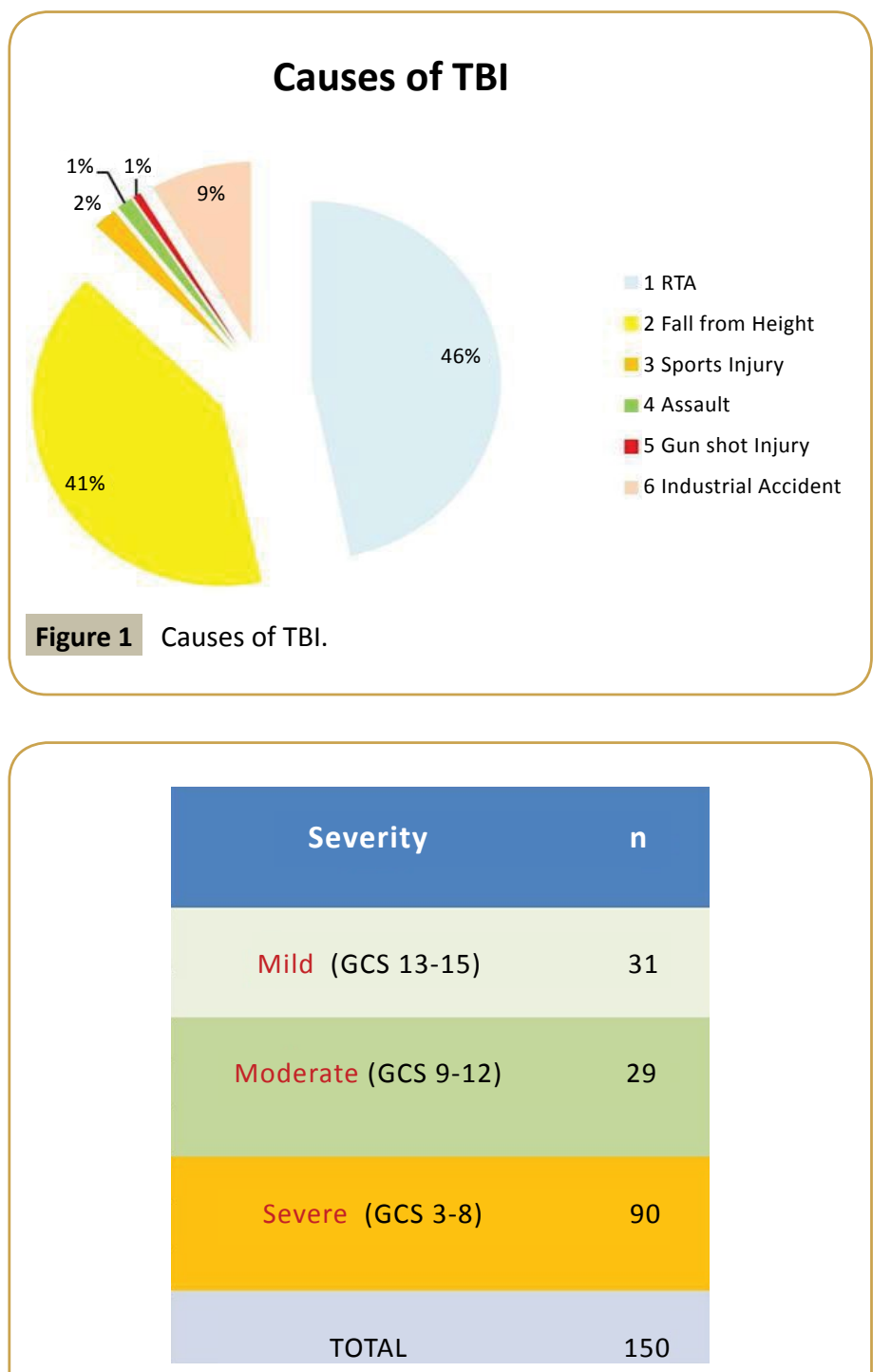

Figure 2 TBI severity.

craniectomy, craniotomy with evacuation of hematoma, external ventricular drainage and intracranial pressure monitoring (ICP) as isolated or in combination with other procedures. While in $46 \%(69 / 150)$ cases, only medical management was provided or neurosurgical intervention was not required. The mean serum sodium level before correction was $131.20 \pm 2.91 \mathrm{SD} \mathrm{mmol} / \mathrm{L}$ and mean serum sodium level after treatment of hyponatremia was $137.58 \pm 2.45 \mathrm{SD} \mathrm{mmol} / \mathrm{L}$ (Table I). Severe hyponatremia (serum sodium $<125 \mathrm{mmol} / \mathrm{L}$ ) was seen only in $3 \%$ (4/150) cases, with lowest value of $117 \mathrm{mmol} / \mathrm{L}$. The mean duration of onset of hyponatremia remained $7.74 \pm 7.00$ SD days after ICU admission. Serum sodium was corrected to normal in $72 \%(108 / 150)$ patients within $48 \mathrm{~h}$ of onset of hyponatremia, while in $28 \%$ $(42 / 150)$ cases it took longer than $48 \mathrm{~h}$ to be corrected due to delayed or wrong diagnosis of hyponatremia. In 98\% (147/150) patients this correction was achieved by $<12 \mathrm{mmol} / \mathrm{L} / 24 \mathrm{~h}$, while in 3 cases (2\%) exceeded $>12 \mathrm{mmol} / \mathrm{L} / 24 \mathrm{~h}$. The neurological outcome as defined earlier in methods, good outcome was seen in $83 \%(125 / 150)$ patients and poor outcome in $17 \%(25 / 150)$ cases, from all types of TBI (mild, moderate \& severe). While in 90 patients with severe TBI, good neurological outcome was observed in 76\% (68/90) patients \& poor neurological outcome in $24 \%(22 / 90)$ patients (Table 1). Statistical significant association was seen between serum sodium correction within $48 \mathrm{~h}$ of onset (Yes/No) and neurological outcome group (Good/Poor), Chi Square Test ( $X^{2}$ : 19.285; $D f=1 ; P$ value $\left.<0.0001\right)$ (Table 2). This

Table 1 Demographic data and basic information. Total number of patients $(n): 150$.

\begin{tabular}{|c|c|c|}
\hline Age & (Mean) $32.7 \pm$ & 18.24 SD Years \\
\hline $\begin{array}{l}\text { Gender } \\
>\quad \text { Mae } \\
>\quad \text { Female }\end{array}$ & $\begin{array}{l}132(88 \%) \\
18(12 \%)\end{array}$ & \\
\hline $\begin{array}{l}\text { Patient Status } \\
>\quad \text { Discharged from ICU } \\
>\quad \text { Died during ICU Stay }\end{array}$ & $\begin{array}{l}143(95 \%) \\
7(5 \%)\end{array}$ & \\
\hline Length of Stay in ICU & (Mean) 16.16 & 9.8 SD Days \\
\hline $\begin{array}{l}\text { Average GCS } \\
>\quad \text { On admission } \\
>\quad \text { At discharge from ICU }\end{array}$ & $\begin{array}{l}8 \\
12\end{array}$ & \\
\hline $\begin{array}{l}\text { TBI Classification } \\
>\text { Mild } \\
>\text { Moderate } \\
>\text { Severe }\end{array}$ & $\begin{array}{l}31(21 \%) \\
29(19 \%) \\
90(60 \%)\end{array}$ & \\
\hline $\begin{array}{l}\text { TBI Lesions } \\
>\quad \text { Mixed } \\
>\text { Solitary } \\
>\text { DAI }\end{array}$ & $\begin{array}{c}100(67 \%) \\
47(31 \%) \\
3(2 \%)\end{array}$ & \\
\hline Onset of Hyponatremia & (Mean) $7.7 \pm 75$ & D Days \\
\hline $\begin{array}{l}\text { Mean Serum Sodium } \\
>\quad \text { Before treatment } \\
>\quad \text { After treatment }\end{array}$ & $\begin{array}{l}131.20 \pm 2.91 \\
137.58 \pm 2.45\end{array}$ & 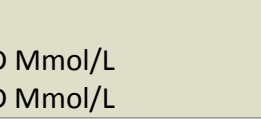 \\
\hline $\begin{array}{l}\text { Serum Sodium Correction } \\
>\quad \text { Yes } \\
>\text { No }\end{array}$ & $\begin{array}{l}\text { in } 48 \mathrm{~h} \\
\qquad \begin{array}{l}108(72 \%) \\
42(28 \%)\end{array}\end{array}$ & \\
\hline $\begin{array}{l}\text { Neurological Outcome } \\
\text { - In all TBI (mild, } \\
\text { moderate, severe) }\end{array}$ & Good 125/150 (83\%) & Poor 25/150 (17\%) \\
\hline - In Severe TBI n: 90 & $68 / 90(76 \%)$ & $22 / 90(24 \%)$ \\
\hline
\end{tabular}

\begin{tabular}{|c|c|}
\hline TBI Categories & $\mathbf{n}$ \\
\hline Mixed Lesions & 100 \\
\hline \multicolumn{2}{|l|}{ Solitary Lesions ( $n: 47)$} \\
\hline EDH & 10 \\
\hline SDH & 16 \\
\hline $\mathrm{CH}$ & 14 \\
\hline $\operatorname{tr} \mathrm{SAH}$ & 5 \\
\hline IVH & 2 \\
\hline DAI & 3 \\
\hline TOTAL & 150 \\
\hline
\end{tabular}

Figure 3 TBI categories. 
Table 2 Association between serum sodium correction within $48 \mathrm{~h}$ and neurological outcome.

\begin{tabular}{c|c|c|c|}
$\begin{array}{c}\text { Neurological } \\
\text { Outcome }\end{array}$ & $\begin{array}{c}\text { Serum Sodium Correction within } 48 \text { h } \\
\text { Yes }\end{array}$ & No & Total \\
\hline Good & $99 / 150(66 \%)$ & $26 / 150(17 \%)$ & $125 / 150(83 \%)$ \\
\hline Poor & $9 / 150(6 \%)$ & $16 / 150(11 \%)$ & $\mathbf{2 5 / 1 5 0 ( 1 7 \% )}$ \\
\hline Total & $\mathbf{1 0 8 / 1 5 0 ( 7 2 \% )}$ & $\mathbf{4 2 / 1 5 0 ( 2 8 \% )}$ & $\mathbf{1 5 0 / 1 5 0 ( 1 0 0 \% )}$ \\
\hline
\end{tabular}

Chi Square Test $(2 \times 2$ Table) X2: 19.285, Df: 1 , P value $<0.0001$

Table 3 Association between neurological outcome and other factors including sodium correction within $48 \mathrm{~h}$ of detection.

\begin{tabular}{|c|c|c|c|c|c|}
\hline Variables & $\begin{array}{l}\text { Odds } \\
\text { Ratio }\end{array}$ & Z-Statistic & P-Value & $\begin{array}{l}\text { Lower limit } \\
95 \% \mathrm{Cl}\end{array}$ & $\begin{array}{l}\text { Upper limit } \\
95 \% \mathrm{Cl}\end{array}$ \\
\hline $\begin{array}{l}\text { Na correction } \\
\text { within } 48 \mathrm{~h}\end{array}$ & 10 & 2.7 & 0.007 & 1.9 & 55 \\
\hline Age & 0.98 & -1.18 & 0.24 & 0.94 & 1.02 \\
\hline $\begin{array}{l}\text { Female } \\
\text { Gender }\end{array}$ & 2.11 & 0.57 & 0.57 & 0.16 & 27 \\
\hline $\begin{array}{l}\text { GCS on } \\
\text { admission }\end{array}$ & 0.51 & -2.86 & 0.003 & 0.33 & 0.8 \\
\hline $\begin{array}{l}\text { GCS on } \\
\text { discharge }\end{array}$ & 3.43 & 4.22 & $<0.001$ & 1.93 & 6.08 \\
\hline
\end{tabular}

Univariate analysis: Odds Ratio (OR) of good neurological outcome if $\mathrm{Na}$ correction done within $48 \mathrm{~h}=5.44$ ( $\mathrm{P}$ value $<0.001,95 \%$ - 2.2-13.48)

Multivariable logistic regression model to assess neurological outcome

association was seen also statistically significant by Univariate and Multivariable Logistic Regression Model (Univariate analysis: odd ratio (OR) of good neurological outcome if $\mathrm{Na}$ correction within $48 \mathrm{~h}=5.44, \mathrm{P}$ value $<0.001, \mathrm{Cl} 95 \%-2.2-13.48)$, (Multivariable Logistic Regression Model to assess neurological outcome, OR for $\mathrm{Na}$ correction within $48 \mathrm{~h}=10, \mathrm{P}$ value 0.007 $\mathrm{Cl} 95 \%$ 1.9-55). Same way, significant association was seen between neurological outcome and GCS at admission (OR 0.51, $P$ value $0.003, \mathrm{Cl} 95 \%$ 0.33-0.8) \& GCS at discharge (OR 3.43, $P$ value $<0.001, \mathrm{Cl} 95 \%$ 1.93-6.08). However, there was no statistical significance between neurological outcome and age (OR 0.98, P value $0.24, \mathrm{Cl} 95 \%$ 0.94-1.02) \& gender (OR 2.11, P value 0.57, Cl 95\% 0.16-27) (Table 3). Receiver operator characteristic Curve for Logistic Model, area under ROC Curve was 0.9731 (Figure 4).

\section{Discussion}

Hyponatremia is very common in traumatic brain injury patients, and it is one of significant risk factor leading to secondary brain injuries [5]. The risk of complications like cerebral edema is more within first $48 \mathrm{~h}$ of onset due to water shift into brain cells because of low osmolality as compared to chronic hyponatremia (onset $>48 \mathrm{~h}$ ), as most of compensatory mechanisms are not fully developed in acute hyponatremia [11-15]. Thus, if hyponatremia is corrected appropriately within this duration, serious complication like malignant brain edema can be prevented. Our study was designed to know the effect of hyponatremia correction within first $48 \mathrm{~h}$ of onset on neurological outcome in traumatic brain injury patients, who were admitted to ICU. In our study, we found road traffic accident (RTA) most common cause leading to TBI and majority of these patients were young male. In 108 patients serum sodium was normalized within $48 \mathrm{~h}$ of detection of hyponatremia and in 42 patients, it took more than $48 \mathrm{~h}$ to correct. In 125 cases, good neurological outcome was observed and poor outcome in 25 patients. We found a significant association between early correction of hyponatremia within 48 $\mathrm{h}$ of detection and neurological outcome in these patients. I could not find any exactly similar study in the literature to compare my results, but our study resembled with some recently published studies with common objectives but different variables.

Xiao et al. [20] conducted recently a retrospective analysis on 136 patients with traumatic brain injuries, and he found correlation between developing hyponatremia and factors such as GCS $\leq 8$, cerebral oedema, and a basal skull fracture. In his study, by multivariate logistic regression analysis he found a strong association between occurrence of hyponatremia and a GCS $\leq$ $8(P<0.016)$, presence of cerebral edema $(P<0.001)$, and a basal skull fracture $(P<0.001)$, but no statistical significant association between occurrence of hyponatremia and age $(P>0.05)$ and gender $(P=0.347)$. In our study, there were 90 cases with GCS $\leq$ 8 who had developed hyponatremia during ICU stay. We found a significant association between correction of hyponatremia within $48 \mathrm{~h}$ and neurological outcome based upon GCS scoring (OR 5.44, P Value<0.001, Cl 95\% - 2.2-13.48), but no statistically significant association between neurological outcome and age \& gender ( $P$ value $0.29 \& 0.58$, respectively). These results are little comparable to his study, anyhow he measured only epidemiology of hyponatremia and we measured association between neurological outcome and sodium correction within $48 \mathrm{~h}$ of onset.

Georg et al. [21] conducted a large multicenter retrospective analysis on 77 ICUs (medical, surgical \& mixed ICUs) on 151486 patients and determined that dysnatremia is independent risk factor for increased mortality in critically ill patients. He included all the patients at the time of ICU admission who had hyponatremia or hypernatremia. He found that all grades of hyponatremia (mild, moderate \& severe) were associated with increased risk of mortality, OR and $95 \%$ confidence interval for borderline, mild \& severe hyponatremia were 1.32 (1.25-1.39), 1.89 (1.71-2.09) and 1.81 (1.56-2.10), respectively. We had single center study and only traumatic brain injury patients with hyponatremia were analyzed,

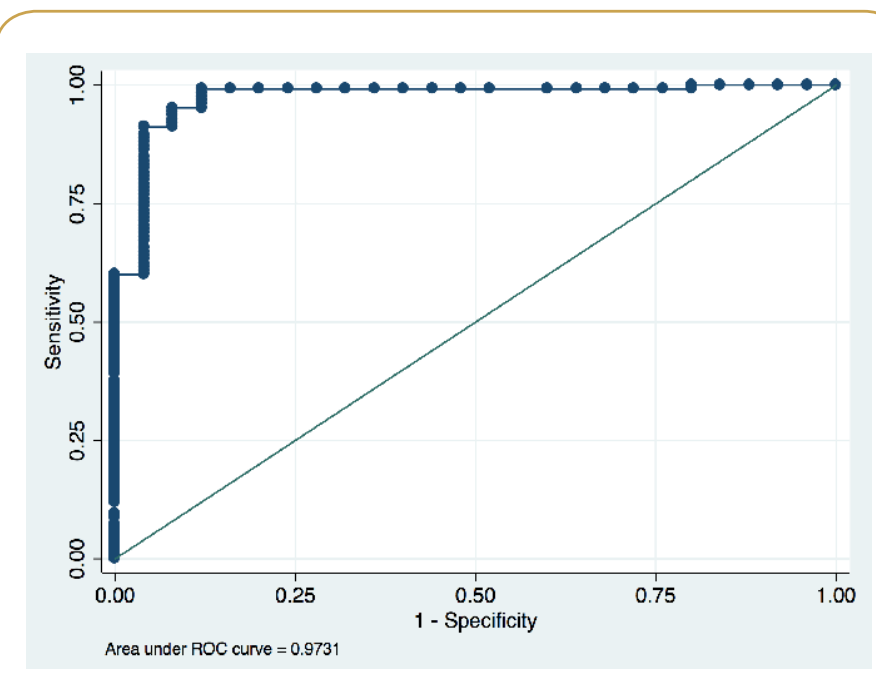

Figure 4 Receiver operator characteristic curve for logistic model. 
in contrast to his multicenter and all population of ICU patients who had dysnatremia. He included all dysnatremic patients on admission to ICU, while we had analysis on only TBI patients who developed hyponatremia during ICU stay after admission. He had $1.2 \%$ of cases with severe hyponatremia, while we had $3 \%$ (4/150) cases with severe hyponatremia. Overall ICU mortality in his study was $12 \%$, while it was only $2 \%(3 / 147)$ in ours. Mean age was $62 \pm 16$ in his study population, while it was 32.73 years in our study. The average LOS was 16 days in our study, while it was 4 days in his study. The main strength of our study remained that we measured neurological outcome on the basis of serum sodium correction within acute phase ( $<48 \mathrm{~h}$ of onset), when the chances of severe cerebral edema are more due to shift of water into brain cells because of hypo-osmolality. While, he measured only the consequences of dysnatremia. He did not measure the effect of any intervention on overall outcome in these patients.

Gopinath et al. [22] conducted a prospective study and measured effect of arterial hypoxia as a cause of secondary brain injury on neurological outcome in patients with severe traumatic brain injury $(\mathrm{GCS} \leq 8)$. He used fiber optic catheter to detect jugular venous desaturation $\left(\mathrm{SjvO}_{2}\right)$ in 116 patients admitted with severe head injuries and found significant association between $\mathrm{SjvO}_{2}$ and poor neurological outcome. His study was comparable to ours in few aspects, 90 per cent of patients studied were male, with average age of $31.5 \pm 14.7$ years. We had $60 \%$ cases with severe TBI, while he had all patients included in the study with severe TBI. Mean age was 32.7 years in our, which remained quite similar to his study, explaining again the higher incidence of traumatic brain injury in young population. However, he used Glasgow Outcome Scale (GOS) to measure neurological outcome, while we used Glasgow Coma Scale (GCS) to measure neurological outcome as long term functional outcome like GOS was not possible in our study due to rapid turn-over of patients from ICU to general ward after stabilizing and treating the initial insults. Moreover, he had prospective study, while we had retrospective analysis in our study and further studies may be required in a prospective fashion.

Dias et al. [23] investigated response of hypertonic saline bolus on intracranial hypertension in traumatic brain injury patients, and he found significant reduction of intracranial pressure after intravenous bolus of hypertonic saline. Devin et al. [24] conducted a study on animal model by using osmotic transport device (OTD) in patients with traumatic brain injury who had severe cerebral oedema and he found significantly improved functional neurological outcome in OTD treated patients. Both these studies above indicate that any factor causing reduction in cerebral oedema in acute traumatic brain injury patients, can improve neurological outcome. Our study was based upon the similar concept of correcting hyponatremia in acute phase (within $48 \mathrm{~h}$ of onset) when there is increased risk of cerebral oedema, which if treated appropriately can improve the neurological outcome.

\section{Limitations of Study}

We had some limitations in our study. Firstly, it was retrospective analysis, while many studies done in past are prospective while determining outcome. It was a single center study, further multicenter studies on a large sample size may be required further to validate this concept. We used Glasgow Coma Scale as a tool for outcome, while in many studies done in past to measure the neurological outcome, Glasgow Outcome Scale had been used as a tool for neurological outcome.

\section{Conclusion}

Hyponatremia is one of the important factors affecting neurological outcome. Timely and effective correction of hyponatremia may improve outcome in patients with traumatic brain injury. Its early correction within acute phase (within $48 \mathrm{~h}$ of onset), when there is increased risk of cerebral oedema, can improve neurological outcome significantly.

\section{Authors Contribution}

1. Khalil Ahmad: Main conception \& design of study, manuscript drafting.

2. Zeyad Faoor Alrais: Critical revision of manuscript.

3. Hesham Mohamed Elkholy: Acquisition of data.

4. Adel Elsaid Elkhouly: Draft revision.

5. Maged Mohsen Beniamein: Acquisition \& Interpretation of data.

6. Ammar Mohamed Abdelhadi: Acquisition \& Interpretation of data.

7. Sohail Majeed: Participated in Study Protocol \& data interpretation.

8. Ahmad Shoaib: Data Analysis.

\section{Ethical Approval}

Prior approval was taken from local ethical committee, Medical Research Committee, Dubai Health Authority. Ref: MRC05/2014-10.

\section{Acknowledgement}

Basic data was analyzed by Miss Annie Sumithero, our hospital biostatician. However, there was no financial compensation for that. Logistic Regression analysis was done by Dr. Ahmad Shoaib, Senior clinical research fellow University of Hull \& University of York, and Specialist Registrar Cardiology Whiston Hospital UK. Special regards to Dr. Zeyad Alrais, consultant \& head of critical care section for critically revision of manuscript. 


\section{References}

1 Cole CD, Oren N, Gottfried MD, Liu JK, Couldwell WT (2004) Hyponatraemia in the neurosurgical patient: Diagnosis and management. Neurosurg Focus 16: 4.

2 Tisdall M, Crocker M, Watkiss J, Smith M (2006) Disturbances of sodium in critically ill neurologic patients. J Neurosurg Anesthesio 18: 57-63.

3 Hannon MJ, Crowley RK, Behan LA, O Sullivan EP, O Brien MM, et al. (2013) Acute glucocorticoid deficiency and diabetes insipidus are common after acute traumatic brain injury and predict mortality. J Clin Endocrinol 98: 3229-3237.

4 Moro N, Katayam Y, Igarashi T, Mori T, Kojima J (2007) Hyponatraemia in patients with traumatic brain injury: Incidence, mechanism and response to sodium supplementation or retention therapy with hydrocortisone. Surg Neurol 68: 387-393.

5 Haddad SH, Arabi YM (2012) Critical care management of severe traumatic brain injury in adults. Scand J Trauma Resusc Emerg Med 20: 12.

6 Sterns RH, Silver SM (2006) Brain volume regulation in response to hypo-osmolality and its correction. Am J Med 119: 12-16.

7 Sherlock M, O'Sullivan E, Agha A, Behan LA, Rawluk D, et al. (2006) The incidence and pathophysiology of hyponatraemia after subarachnoid haemorrhage. J Clin Endocrinol 64: 250-254.

8 Verbalis JG, Goldsmith SR, Greenberg A, Korzelius C, Schrier RW, et al. (2013) Diagnosis, evaluation and treatment of hyponatraemia: Expert panel recommendations. Am J Med 126: 6.

9 Corona G, Giuliani C, Parenti G, Norello D, Verbalis JG, et al. (2013) Moderate hyponatraemia is associated with increased risk of mortality: Evidence from a meta-analysis. PLoS One 8: e80451.

10 Diringer MN, Zazulia AR (2006) Hyponatremia in neurologic patients: consequences and approaches to treatment. Neurologist 12: 117126.

11 Spasovski G, Vanholder R, Allolio B, Djillali A, Steve B, et al. (2014) Clinical practice guideline on diagnosis and treatment of hyponatremia. Intensive Care Med 40: 320-331.

12 Sherlock M, O'Sullivan E, Agha A, Behan LA, Owens D, et al.
(2009) Incidence and pathophysiology of severe hyponatremia in neurosurgical patients. Postgrad Med J 85: 171-175.

13 Clayton JA, le Jeune IR, Hall IP (2006) Severe hyponatremia in medical in-patients: Aetiology, assessment and outcome. QJM 99: 505-511.

14 Nzerue CM, Baffoe-Bonnie H, You W, Falana B, Dai S (2003) Predictors of outcome in hospitalized patients with severe hyponatremia. J Natl Med Assoc 95: 335-343.

15 Sterns RH, Silver SM (2006) Brain volume regulation in response to hypo osmolality and its correction. Am J Med 119: S12-S16.

16 Gill G, Huda B, Boyd A, Skagen K, Wile D, et al. (2006) Characteristics and mortality of severe hyponatremia-A hospital-based study. J Clin Endocrinol 65: 246-249.

17 Khalil A, Zeyad FA, Hesham ME (2015) Effect of early correction of hyponatremia on neurological outcome in traumatic brain injury [abstract] ESICM LIVES. Intensive Care Med Experimental 3: A817.

18 Jennet B, Teasdale G (1977) Aspects of coma after severe head injury. Lancet 1: 1878-1881.

19 Jennet B, Teasdale G, Galbraith S, Pickard J, Grant H, et al. (1977) Severe head injuries in three countries. J Neurosurg Psychiatry 40: 291-298.

20 Xiaofeng M, Baozhong S (2016) Traumatic brain injury patients with a Glasgow coma scale score of $\leq 8$, cerebral edema, and/or a basal skull fracture are more susceptible to developing hyponatremia. J Neurosurg Anesthesiol 28: 21-26.

21 Georg CF, Gregor L, Wilfred D, Barbara M, Christoph S, et al. (2010) Incidence \& prognosis of dysnatremias present on ICU admission. Intensive Care Med 36: 304-311.

22 Gopinath SP, Robertson CS, Contant CF, Hayes C, Feldman Z, et al. (1994) Jugular venous desaturation and outcome after head injury. J Neurol Neurosurg and Psychiatry 57: 717-723.

23 Dias C, Silva MJ, Pereira E, Silva S, Cerejo A, et al. (2014) Posttraumatic multimodal brain monitoring: Response to hypertonic saline. J Neurotrauma 31: 1872-1880.

24 Devin WM, Jenny IS, Chris H, Mike SH, Victor GJR, et al. (2014) Reduction of cerebral edema after traumatic brain injury using an osmotic transport device. J Neurotrauma 31: 1948-1954. 